\title{
CFD ANAL YSIS OF BOEING-737 3D AEROFOIL AND ADVERSE YAW ON THE AEROFOIL
}

\author{
Shubham Prakash Rawool ${ }^{1}$ \\ ${ }^{1}$ Department of Mechanical Engineering, MAEER's MITCOE, Pune, Maharashtra, India
}

\begin{abstract}
In this work, the drag and lift forces along with adverse yaw is obtained using CFD which can also be determined experimentally. The analysis is done on test aerofoil Boeing-737 root section aerofoil. The experimental setup data is taken from Boeing-737 official website. Here the mentioned forces and results are obtained solely by the use of computational fluid dynamics in ANSYS FLUENT (version 17.0). The flow was modelled as incompressible fluid air. The drawing and meshing is done in ANSYS Workbench 17.0. The outcome of this investigation was shown and computed by using ANSYS Workbench 17.0. Finally, the effect of lift and drag forces was found out for different angles of attack from $-4^{\circ}$ to $22^{\circ}$ and also the values of adverse yaw and stall angle are found out for the test aerofoil. The whole analysis is solely based on the principle of finite element method and computational fluid dynamics (CFD).
\end{abstract}

Keywords: Boeing-737, aerofoil, adverse yaw, CFD, ANSYS FLUENT, stall angle.

\section{INTRODUCTION}

Aerodynamic problems in general are often difficult to solve by analytical or practical analysis. This research presents the modeling and simulation through CFD on an aircraft wing model, using typical root aerofoil section of Boeing 737 aircraft.

The CFD analysis is an alternative to predict the aerodynamic characteristics of the tested wing model. The flow of air over the aerofoils is most important during designing aerodynamic objects.

\subsection{Field of Study}

Aerofoil is an important part of any structure moving in a fluid whether it may be a passenger plane, jet plane or helicopter. The airfoils decide whether the lift force is sufficient to balance the weight of the structure or not and how much drag force is being applied on the structure. Symmetrical and asymmetrical are the two basic types of aerofoil. However modern aerofoils are complex and difficult to categorize. For this study, the aerofoil shape at the root of wing of Boeing-737 is used. Experimental analysis involves a lot of practical difficulties ranging from making and fixing the aerofoil to the cost of setup. Other problems like changing continuously the angle of attack and carrying out the experiment with depleting resources are difficult to counter. CFD analysis has turned out very much beneficial during such experiments. Flow analysis becomes more effective as it investigates everything more thoroughly than experimental method. ANSYS is vast computational software that enables researchers to analyze the problems related to different engineering sectors.

\subsection{Background of Study}

Propellers, airplane wings, helicopter blades all work on the same principle, making effective use of aerofoil structures. An aerofoil generates aerodynamic forces when placed in flowing fluid. These forces are of two basic nature. Lift force is in direction perpendicular to direction of fluid flow whereas, drag force is in the direction of fluid flow. When fixed in suitable angle then the aerofoil divides the incoming flow. Now different effects and principles work together to apply the lift and drag forces. The Bernoulli's principle in fluid dynamics and Newton's third law of motion are collectively responsible for the lift of aerofoil. It is extremely important to accurately know the lift and drag force that will act on aerofoil while lifting the helicopters or pulling the propeller planes. While modelling and simulating in ANSYS FLUENT certain conditions like incompressible fluid flow were observed in the model. ANSYS gives the solution according to the solver used and the given input conditions based on the number of iterations until convergence or divergence occurs. The practical observations slightly vary from the ANSYS solution due to anomalies in practical flow.

\subsection{Necessity of Analysis}

An aeroplane has to be continuously maneuvered. Taking off from ground level, cruising, taking a turn, rolling, pitching, yawing, landing on ground, etc. In order to accurately counter the adverse aerodynamic effects while maneuvering, it is important to know the forces acting on the structure. A complete analysis of test aerofoil moving in air at various angles of attack and thenumerical value of adverse yaw found out through analysis on ANSYS FLUENT is stated in this research. 


\section{LITERATURE SURVEY}

MD. Safayet Hossain, Muhammad Ferdous Raiyan, Mohammed Nasir Uddin Akanda and Nahed Hassan Jony ${ }^{[1]}$ analyzed the flow on two aerofoils namely NACA 6409 and NACA 4412. Their study indicates the static pressure distribution on the mentioned two aerofoils. They comparedthe coefficient of lift to drag ratio to find the better aerofoil amongst the two.

Douvi C. Eleni, Tsavalos I. Athanasios and Margaris P. Dionissios $^{[2]}$ researched on the better turbulence model for NACA 0012 aerofoil CFD analysis amongst the three turbulence models namely Spalart-Allmaras, Realizable k-É and $\mathrm{k}-\varepsilon$ and $\mathrm{k}-\omega$ shear stress transport (SST). The research concluded as $\mathrm{k}-\omega$ SST two equation model gives more practical results than the other two. Considering the obtained results in mentioned research paper, $\mathrm{k}-\omega$ shear stress transport (SST) is used for this analysis.

Jeyo Paul, Ajo Alexander and Manikandan $S^{[3]}$ researched on NACA 4412 aerofoil and analyzed the velocity profile over the aerofoil with increasing angle of attack. The result suggested that the lift force increases as angle of attack is increased. The analysis was done with $51 \mathrm{~m} / \mathrm{s}$ air speed. The meshing was done in GAMBIT software.

Chandrakant Sagat, Pravin Mane and B S Gawali ${ }^{[4]}$ collectively did an experimental as well as CFD analysis on aerofoil. The analysis was done with $15 \mathrm{~m} / \mathrm{s}$ of air flow over aerofoil for various angles of attack from $0^{\circ}$ to $20^{\circ}$. The results of said research paper demonstrated the pressure distribution over the aerofoil and action of lift force on aerofoil.

\section{MODELLING, MESHING AND BOUNDARY CONDITIONS}

The test section is designed in ANSYS design modeler. The root aerofoil section of Boeing-737 is used in this analysis.

\subsection{Design Parameters}

The test section is designed based on the dimensions obtained in the Boeing-737 official website ${ }^{[6]}$.The parameters used from the website and other references are as follows:

\subsubsection{Chord Length}

The chord length is the length of the straight line joining the leading edge and trailing edge of aerofoil. The chord length is obtained from the Boeing-737 official website ${ }^{[6]}$ for the original Boeing-737 root section. The chord length is $7.32 \mathrm{~m}$.

\subsubsection{Curve Coordinates}

The coordinates of the aerofoil section are obtained from 'airfoiltools.com ${ }^{,[7]}$ which is a database for NACA aerofoils and various other aerofoils.

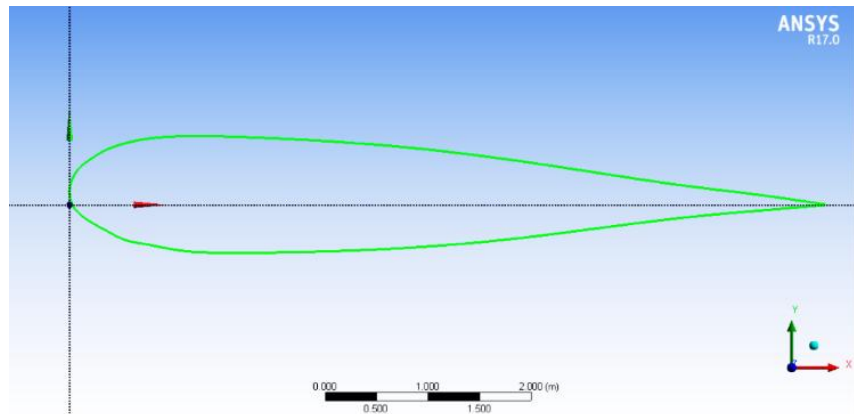

Fig -1:Aerofoil curve of root section of Boeing-737

\subsubsection{Control Volume}

Enclosure is the control volume for this analysis. A rectangular control volume is chosen for this analysis as it is simple in construction and has negligible boundary effect on flow. Enough distance was kept between the aerofoil and the walls of the control volume. Also the walls are of symmetry type to avoid any no slip condition. However the aerofoil surface is wall type and hence causes wall-fluid friction and drag force.

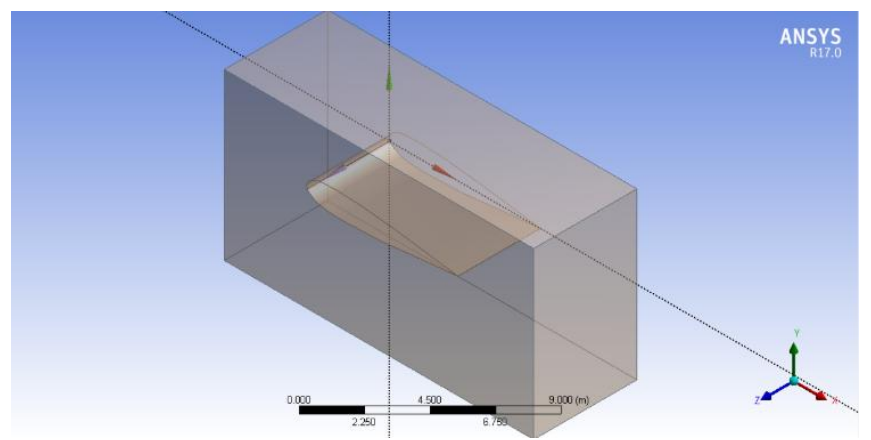

Fig -2:Isometric view of control volume

\subsection{Meshing}

The complete meshing was done in ANSYS FLUENT and face sizing along with element sizing was used in the complicated areas of the model like the leading edge of the aerofoil as well as the trailing edge of the same. Inflation was established around the curve of the aerofoil as flow variation was to be studied in this area. Face sizing was adjusted on the curved surface of aerofoil to get more accurate results on the surface. Tetrahedral meshing was used to generate a fine mesh.

Table -1: Mesh Parameters

\begin{tabular}{|l|l|}
\hline Number of Nodes & 103448 \\
\hline Number of Elements & 442144 \\
\hline
\end{tabular}




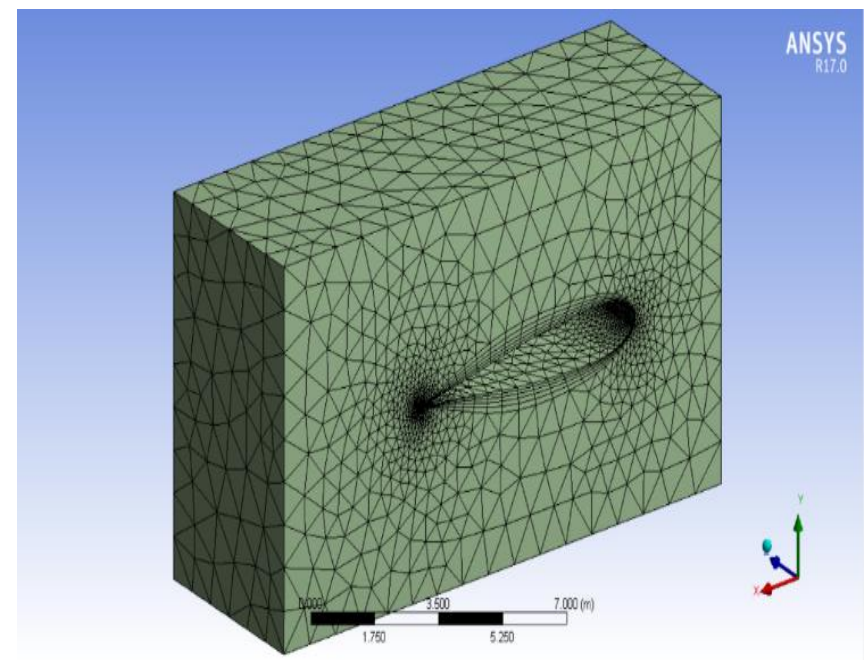

Fig -3:Meshing of control volume

\subsection{Boundary Conditions}

The fluid used is compressible air. The velocity is kept same as the cruising speed of the Boeing-737 obtained from its official website ${ }^{[5]}$. The mesh is then exported to ANSYS FLUENT 17.0 Setup along with physical properties and initial conditions specified.

Table -2: Boundary Conditions

\begin{tabular}{|l|l|}
\hline Inlet velocity & $180 \mathrm{~m} / \mathrm{s}$ \\
\hline $\begin{array}{l}\text { Gauge pressure at inlet and } \\
\text { outlet }\end{array}$ & $0 \mathrm{~Pa}$ \\
\hline Airfoil material & Aluminium \\
\hline Air density & $1.225 \mathrm{~kg} / \mathrm{cm}^{2}$ \\
\hline Ambient temperature & $288.16 \mathrm{~K}$ \\
\hline Dynamic Viscosity & $1.7894 \mathrm{e}-05 \mathrm{~kg} / \mathrm{m}-\mathrm{s}$ \\
\hline
\end{tabular}

\section{RESULTS AND DISCUSSION OF ANALYSIS} OF AEROFOIL

The solution was obtained after standard initialization for various angle of attack between $-4^{\circ}$ to $22^{\circ}$. The results for velocity and pressure distribution is obtained and then the stall angle is calculated through ratio of coefficient of lift and drag. The adverse yaw is calculated after the drag on the aerofoil is known.

\subsection{Velocity Distribution}

The velocity contour is obtained around the aerofoil for angles of attack $-4^{\circ}, 0^{\circ}, 2^{\circ}, 4^{\circ}, 6^{\circ}, 10^{\circ}$ is shown below. The observations from this velocity contours for varying angle of attacks are explained further.

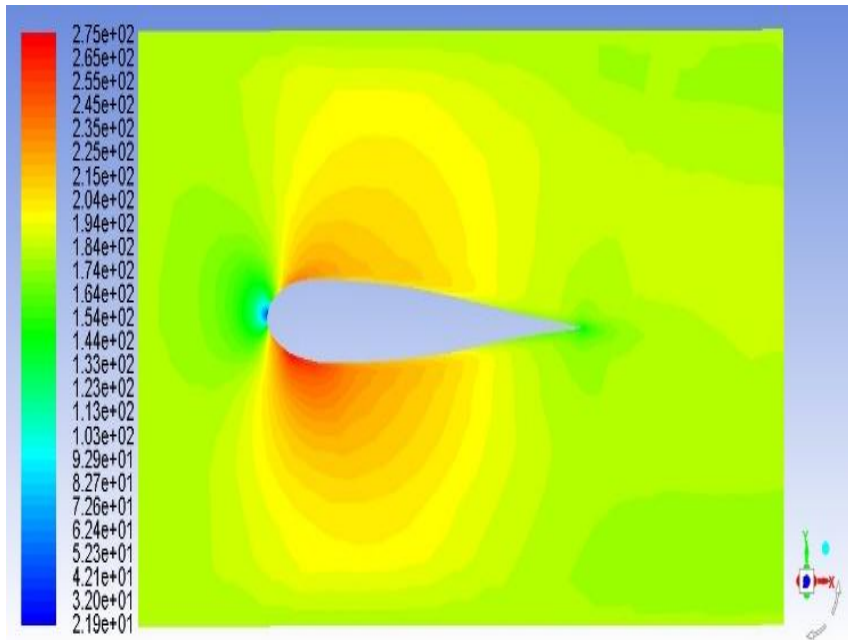

Fig -4: Velocity contour for $-4^{\circ}$ angle of attack

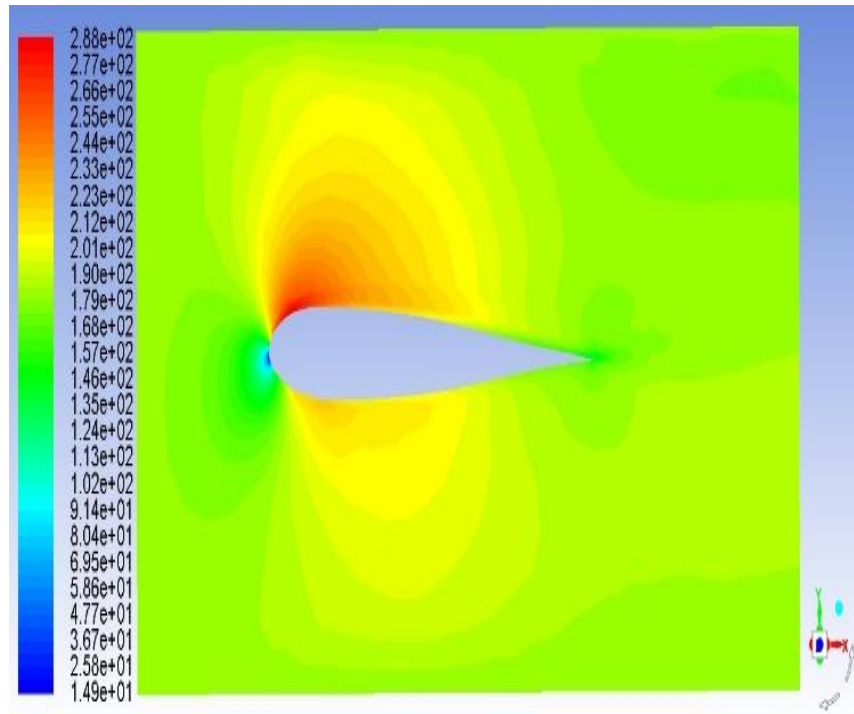

Fig -5: Velocity contour for $0^{\circ}$ angle of attack

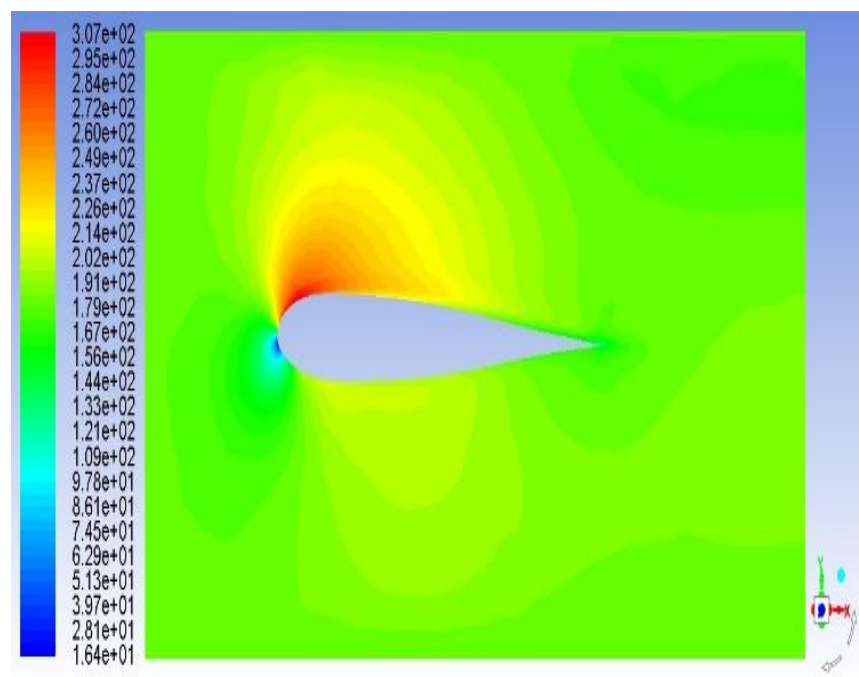

Fig -6: Velocity contour for $4^{\circ}$ angle of attack 


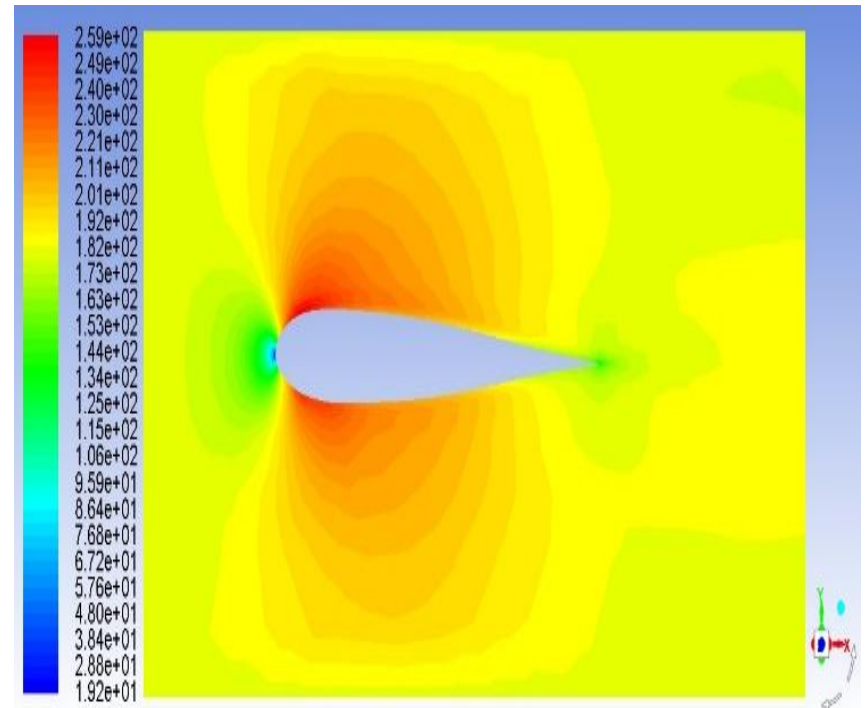

Fig -7: Velocity contour for $6^{\circ}$ angle of attack

We can clearly observe that for positive angle of attack velocity above aerofoil is more than the velocity below the aerofoil unlike the velocity distribution for negative angle of attack. The change in velocity causes change in pressure according to Bernoulli's principle in fluid dynamics. This difference in pressure above and below the aerofoil causes lift force to act perpendicular to the direction of flow. The low velocity area at the leading edge is formed as the incoming air hits perpendicularly to the aerofoil. Friction force and other factors result in a drag force being acted upon the aerofoil.

\subsection{Pressure Distribution}

The pressure distribution is obtained for varying angles of attack $-4^{\circ}, 0^{\circ}, 4^{\circ}, 6^{\circ}$.

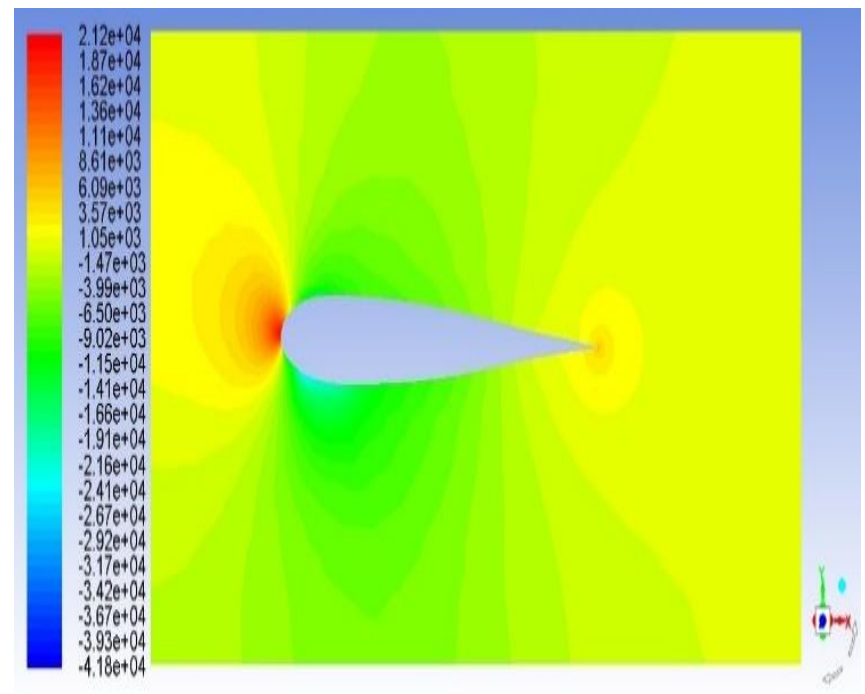

Fig -8: Velocity contour for $-4^{\circ}$ angle of attack

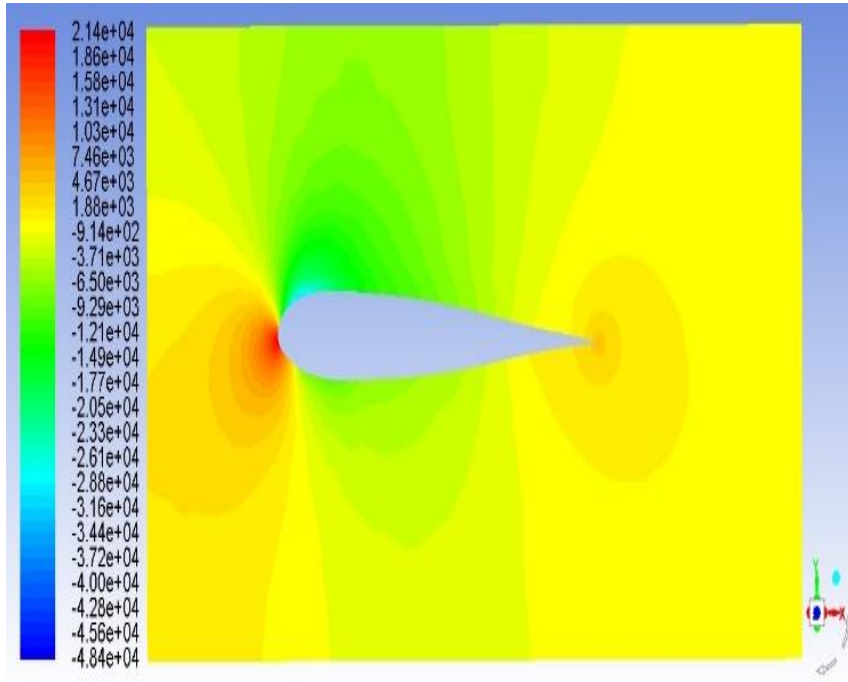

Fig -9: Velocity contour for $0^{\circ}$ angle of attack

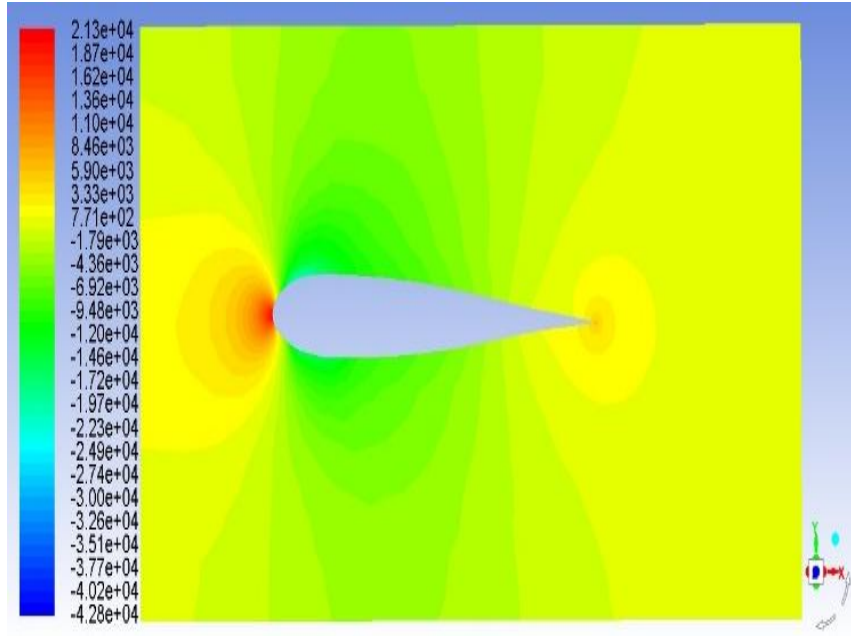

Fig -10: Velocity contour for $4^{\circ}$ angle of attack

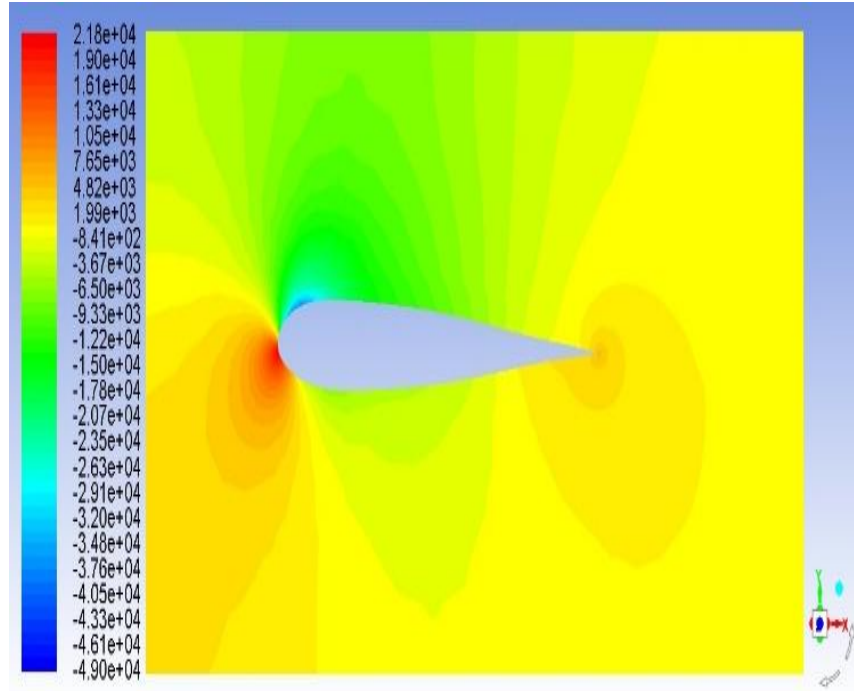

Fig -11: Velocity contour for $6^{\circ}$ angle of attack

As seen in the velocity contours, low pressure area is found above the aerofoil and a comparatively high pressure area is found below the aerofoil for positive angle of attacks. The lift force acts due to this change in pressure. For negative 
angle of attack the lift force acts downwards whereas for $0^{\circ}$ angle of attack a very small positive lift force exists. We can see that as angle of attack increases the lift force increases. A high pressure area is seen at the leading edge of the aerofoil which occurs due to the same reason as explained earlier for the occurrence of low velocity area at the leading edge. This is called as the stagnation point.

\subsection{Coefficients of Lift and Drag}

The coefficient of lift and drag are obtained by the below mentioned formula:

$$
\begin{gathered}
\mathrm{F}_{\text {lift }}=0.5 * \mathrm{C}_{\mathrm{l}} * \rho * \mathrm{v}^{2} * \mathrm{~S} \\
\mathrm{~F}_{\text {drag }}=0.5 * \mathrm{C}_{\mathrm{d}} * \rho * \mathrm{v}^{2} * \mathrm{~S}
\end{gathered}
$$

where, $\rho:$ density of air $=1.225 \mathrm{~kg} / \mathrm{m}^{2}$

$\mathrm{v}$ : velocity of air $=180 \mathrm{~m} / \mathrm{s}$

$\mathrm{S}:$ plan area of the aerofoil $=4 * 7.32=29.28 \mathrm{~m}^{2}$

$\mathrm{C}_{1}$ : Coefficient of lift of aerofoil

$\mathrm{C}_{\mathrm{d}}$ : Coefficient of drag of aerofoil

For different angles of attack the coefficients of lift and drag obtained through CFD analysis on ANSYS 17.0 are:

Table -3: Coefficients of lift and drag for varying angle of attack

\begin{tabular}{|l|l|l|l|}
\hline $\begin{array}{l}\text { Angle of } \\
\text { Attack }\end{array}$ & $\begin{array}{l}\text { Coefficient } \\
\text { of } \operatorname{Lift}\left(\mathrm{C}_{\mathrm{l}}\right)\end{array}$ & $\begin{array}{l}\text { Coefficient } \\
\text { of Drag }\left(\mathrm{C}_{\mathrm{d}}\right)\end{array}$ & $\mathrm{C}_{\mathrm{l}} / \mathrm{C}_{\mathrm{d}}$ \\
\hline$-4^{\mathrm{o}}$ & -0.15651 & 0.00371 & - \\
\hline $0^{\mathrm{o}}$ & 0.06657 & 0.01080 & 6.163889 \\
\hline $2^{\mathrm{o}}$ & 0.18085 & 0.00974 & 18.56776 \\
\hline $4^{\mathrm{o}}$ & 0.31023 & 0.00460 & 67.4413 \\
\hline $6^{\mathrm{o}}$ & 0.45928 & 0.00536 & 85.68657 \\
\hline $8^{\mathrm{o}}$ & 0.62906 & 0.02081 & 30.22874 \\
\hline $10^{\mathrm{o}}$ & 0.81586 & 0.04232 & 19.27836 \\
\hline $12^{\mathrm{o}}$ & 1.01349 & 0.07026 & 14.42485 \\
\hline $14^{\circ}$ & 1.21652 & 0.10482 & 11.6058 \\
\hline $16^{\circ}$ & 1.42109 & 0.14597 & 9.735494 \\
\hline $20^{\circ}$ & 1.81190 & 0.24439 & 7.413969 \\
\hline $22^{\circ}$ & 1.72736 & 0.21639 & 7.982624 \\
\hline
\end{tabular}

From these coefficients of lift and drag, their ratio is obtained which indicates how much effective the aerofoil will be, for the specific angle of attack.

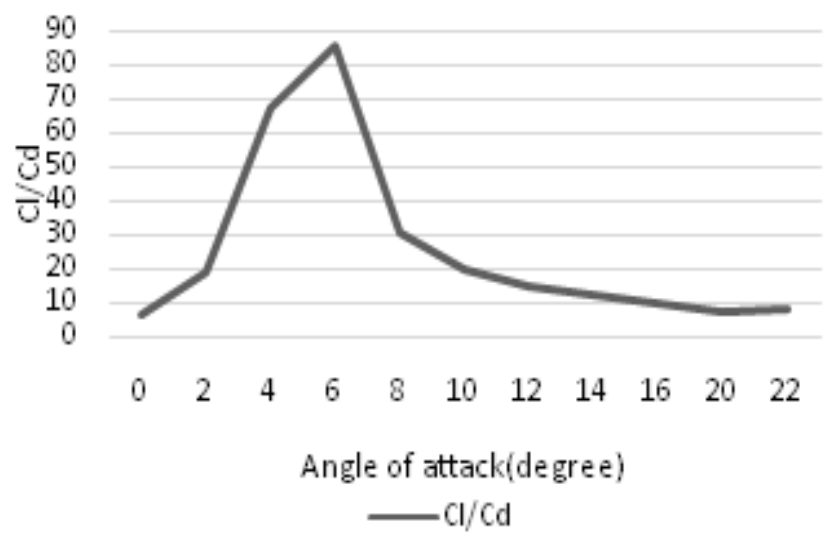

Chart -1: Variation of ratio of coefficients of lift to drag with angle of attack

From the graph we can notice that ratio of coefficient of lift to drag first increases and then decreases. The maximum ratio is obtained at $6^{\circ}$. As the angle of attack increases the coefficient of lift also increases. But after $6^{\circ}$ angle of attack there is rapid increase in coefficient of drag as compared to coefficient to lift.

\subsection{Stall Angle}

As the angle of attack is kept on increasing at a certain angle the flow separation occurs which results in sudden increase in drag force and drag coefficient. This angle is stall angle which can be determined from the following graph.

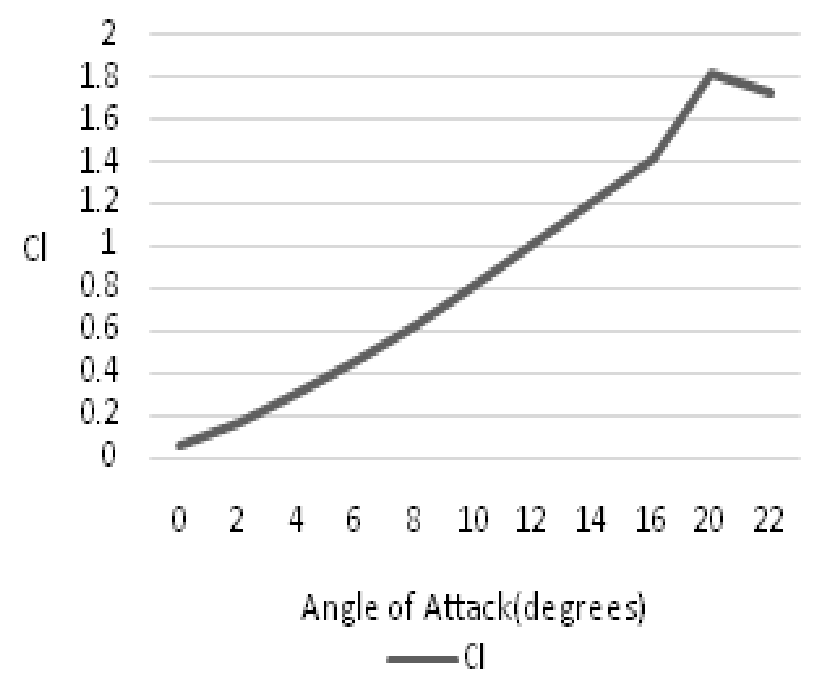

Chart -2: Variation of coefficient of lift with angle of attack

In the above graph, we can observe that the coefficient of lift fist increases and then starts decreasing from $20^{\circ}$ angle of attack. So the stall angle which is the angle of attack at which the coefficient of lift starts falling down even with increasing angle of attack, for the test aerofoil is $20^{\circ}$. 


\section{ADVERSE YAW}

In the chart 2 , we can observed that the coefficient of lift fist increases and then starts decreasing from $20^{\circ}$ angle of attack. So the stall angle which is the angle of attack at which the coefficient of lift starts falling down even with increasing angle of attack, for the test aerofoil is $20^{\circ}$.

When an aeroplane tries to turn either left or right it makes use of aerodynamic forces on it to change its direction of motion instead of a pure yaw. While turning an aeroplane, it performs a roll so that the lift force inclines to the vertical of original direction of motion. As the aeroplane rolls, the angle of attack of attack of outside wing increases with respect to the inside wing thus the $C_{1} / C_{d}$ ratio increases significantly for the outside wing with larger angle of attack. This also results in an increase in drag force on the outside wing which tends to pull back the aeroplane.

The overall result is an application of moment on the plane which tries to oppose the turning of the aeroplane.

Taking the instance of $4^{\circ}$ angle of attack

Drag Coefficient $\mathrm{C}_{\mathrm{d}}-0.00460$

Calculating the drag force -

$\mathrm{F}_{\mathrm{d}}=0.5 * \rho * \mathrm{v}^{2} * \mathrm{~S} * \mathrm{C}_{\mathrm{d}}$

$\rho:$ density of fluid $=1.225 \mathrm{~kg} / \mathrm{m}^{3}$

$\mathrm{v}$ : velocity of aerofoil in direction of fluid flow $=180 \mathrm{~m} / \mathrm{s}$

$\mathrm{S}:$ Plan area of wing $=29.28 \mathrm{~m}^{2}$

$\mathrm{F}_{\mathrm{d}}=2672.8833 \mathrm{~N}$ (obtained through CFD analysis)

Assumption:

The drag force is uniformly distributed about the aerofoil as the aerofoil is extruded to $4 \mathrm{~m}$ with constant thickness and constant chord.

Calculating Adverse Yaw at one end of leading edge, $(\mathrm{r}=4 / 2=2)$

$\mathrm{M}=\mathrm{F}_{\mathrm{d}} * \mathrm{r}$

$\mathrm{M}=5345.7666 \mathrm{Nm}$

Thus, the adverse yaw for $4^{\circ}$ angle of attack of test aerofoil gives an adverse yaw of $5345.76 \mathrm{~N} / \mathrm{m}$.

\section{CONCLUSION}

The analysis successfully completed only after proper selection and designing of aerofoil along with all the required steps and assumptions to be used in the analysis in ANSYS FLUENT (version 17.0).

$>$ With increasing angle of attack the lift force was observed to be increasing along with the drag force. But the latter showed only a small increase initially as this force is mostly controlled by friction and the force thrusted by fluid while it opposes the flow to some degree.

$>$ The optimum angle of attack was found out to be $6^{\circ}$.

$>$ The stall angle at which there is fall in lift force is due to the formation of eddies as the flow separates beyond the aerofoil was $20^{\circ}$.
$>$ The effect of adverse yaw was analyzed and calculated which opposes the turning of aircraft during flight.

A useful and efficient analysis was done in CFD which was otherwise practically difficult.

\section{REFERENCES}

[1]. MD. Safayet Hossain, Muhammad Ferdous Raiyan, Mohammed Nasir Uddin Akanda, Nahed Hassan Jony, A Comparative Flow Analysis Of NACA 6409 AND NACA 4412 Aerofoil, IJRET: International Journal of Research in Engineering and Technology, Volume: 03 Issue: 10 Oct2014

[2]. Douvi C. Eleni, Tsavalos I. Athanasios and Margaris P. Dionissios, Evaluation of the turbulence models for the simulation of the flow over a National Advisory Committee for Aeronautics (NACA) 0012 airfoil, Journal of Mechanical Engineering Research Vol. 4(3), pp. 100-111, March 2012

[3]. Jeyo Paul, Ajo Alexander \& Manikandan S , CFD Analysis of Velocity Profiles for NACA 4412 Aerofoil, Imperial Journal of Interdisciplinary Research (IJIR), Vol-2, Issue-5, 2016

[4]. Chandrakant Sagat, Pravin Mane and B S Gawali, Experimental and CFD analysis of airfoil at low Reynolds number, International Journal of Mechanical Engineering and Robotics Research, ISSN 2278 - 0149 Vol. 1, No. 3, October 2012

[5]. S.Kandwal, Dr. S. Singh, Computational Fluid Dynamics Study Of Fluid Flow And Aerodynamic Forces On An Airfoil, Papers from Conference Proceedings, International Journal of Engineering Research \& Technology (IJERT), Vol. 1 Issue 7, September - 2012 [6]. http://www.b737.org.uk/

[7]. http://airfoiltools.com/

\section{BIOGRAPHY}

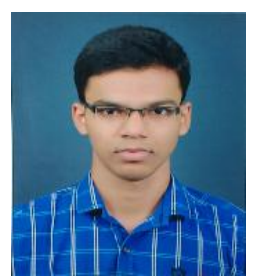

Shubham Prakash Rawool was born in 1996 in Maharashtra, India. He is now pursuing his Bachelors in Mechanical Engineering from Savitribai Phule Pune University (SPPU). His research interests include Computational Fluid Dynamics, Aerodynamics, Heat Transfer, Material Science, Turbo Machinery and Thermodynamics. 